\title{
Enhancement of photocurrent by incorporation of Preyssler type polyoxometalate protected nanoparticles in polyporphyrin films
} Zhaohui Huo, ${ }^{\text {ab }}$ Yiming Liang, ${ }^{b}$ Yaokang Lv, ${ }^{\text {bc }}$ Frédéric Melin, ${ }^{d}$ Petra Hellwig, ${ }^{d}$ Helen Ibrahim, ${ }^{e}$ Michel Goldmann, ${ }^{\mathrm{e}}$ Corinne Boudon, ${ }^{\mathrm{b}}$ Vasilica Badets, ${ }^{\mathrm{b}}$ Antoine Bonnefont, ${ }^{\mathrm{b}}$ and Laurent Ruhlmann ${ }^{\text {b* }}$

The introduction of nanoparticles (MNPs) at the surface of cationic poly-porphyrin films, obtained by electrostatic interaction between the bis-porphyrin copolymer and the Preyssler type polyoxometalate $\mathrm{P}_{5} \mathrm{~W}_{30} @ M N P s$, enhances the photocurrent (up to 2.5-3 times greater as a function of the used nanoparticle).

Polyoxometalates (POMs) form a distinctive class of inorganic metal-oxygen cluster compounds with controllable composition, large structural variety and interesting multifunctional properties and applications in medicine, analytical chemistry, electronics, material science, and catalysis. ${ }^{1}$ POMs are negatively charged electron acceptors, that can undergo a stepwise multielectron reversible redox process without structural changes. ${ }^{2}$ That makes POMs an attractive candidate for the electron exchange process which are the basis for numerous catalytic processes. ${ }^{3}$ In most cases POMs reach excited states only under UV irradiation $(O \rightarrow M$ LMCT absorption band), ${ }^{4}$ which strongly limits the use of POMs in solar visible light conversion materials. To enlarge the practical applications, their association to a visible-light photosensitizer such as porphyrin via covalent ${ }^{5}$ or non-covalent ${ }^{6-7}$ interactions is in consequence required.

In line with this strategy, we have reported a straightforward and efficient electropolymerization procedure $^{8}$ leading to mixed porphyrin-POM copolymer films, involving either Anderson, Dawson or Lindquist type of POMs, with remarkable photoelectrocatalytic properties under visible light illumination. ${ }^{9}$ One noteworthy characteristic of POMs is their ability to act as electron transfer relay, which can promote the transport of photo-generated electrons, avoiding the hole-

\footnotetext{
a. Department of Chemistry, Guangdong University of Education, Guangzhou, 510303, PR China.

b. Université de Strasbourg, Institut de Chimie, UMR CNRS 7177, Laboratoire d'Electrochimie et de Chimie Physique du Corps Solide, 4 rue Blaise Pascal, CS 90032, 67081 Strasbourg cedex, France.E-mail: Iruhlmann@unistra.fr.

College of Chemical Engineering and Materials Science, Zhejiang University of Technology, Hangzhou, 310014, China.

d. Chimie de la Matière Complexe UMR 7140, Laboratoire de Bioélectrochimie et Spectroscopie, CNRS-Université de Strasbourg, 4 rue Blaise Pascal, 67070 Strasbourg, France.

e. Sorbonne Universités, Institut des NanoSciences de Paris, UMR CNRS 7588, Université Paris 6, 4 place Jussieu, boîte courrier 840, F - 75252, Paris, France + Footnotes relating to the title and/or authors should appear here.

Electronic Supplementary Information (ESI) available: [details of any supplementary information available should be included here]. See DOI: 10.1039/x0xx00000x
}

electron recombination, and subsequently improve the photoelectric conversion efficiency. POMs can be used for constructing hybrids inorganic-organic systems, in which the organic dyes act as the electron donors and the POMs act as electron acceptors. It combines the advantages of the high stability of POM clusters with good finely-controllable structure of the organic subunit. ${ }^{10-11}$ In this case, the associated POMcation copolymer of porphyrin could be prepared by exchanging the $\mathrm{PF}_{6}$ - counter ions with Keggin type polyoxometalate. ${ }^{12}$ Such porphyrin-POM electrostatic assemblies could potentially be involved in photoinduced electron transfers from the porphyrin antenna (donor of electron) to the viologen or pyridinium spacers and to the POM (acceptors of electron). These materials are thus promising for the development of photoelectric devices where the type of POMs can be modulated easily.

Besides the above approaches, metal ( $\mathrm{Ag}, \mathrm{Au}$, etc.) plasmonic photoelectrocatalysts are also raising great interests. Indeed, it is well-known that noble metal nanoparticles (NPs) exhibit strong and intense surface plasmon resonance $(S P R)^{13}$ absorption in the visible region and good electrocatalytic activity. Moreover, noble nanoparticles have also received significant attention owing to their excellent electrical properties. These optical and electrical properties can improve the photoelectrocatalytic activity of the hybrid material under visible light irradiation. ${ }^{14}$ POMs can control formation and morphology of metal nanoparticles and serve also as protecting ligands. ${ }^{15}$ POMs decorated-nanoparticles exhibit synergistic enhacement of the photovoltaic or photoelectrocatalytic performance. ${ }^{16}$ With the aim of obtaining a good photoelectrocatalyst, we have used our knowledge to combine porphyrin as a visible light sensitizer with POM as an effective electron relay and with metal nanoparticles as an excellent electronic conductor, amongst other (vide supra). Each step taken in the development of our material was thoroughly characterized by a multitude of techniques. In the first part of this work, metal nanoparticles $(\mathrm{Ag}, \mathrm{Au}, \mathrm{Pt})$ were obtained via an easy one-pot synthesis under environmentally friendly conditions (POMs can act as reductants as well as stabilizers, but also the synthesis is carried out in water at room temperature), ${ }^{17}$ i.e. the photolysis of metal cation solution using Preyssler POM K $\mathrm{K}_{14}\left[\mathrm{NaP}_{5} \mathrm{~W}_{30} \mathrm{O}_{110}\right]$ (abbreviated $\mathrm{P}_{5} \mathrm{~W}_{30}$ ) (step I in Scheme 1 and Fig. S1). UV-Vis absorption spectroscopy was employed to follow the formation of $\mathrm{P}_{5} \mathrm{~W}_{30} @ \mathrm{MNPs}$ (details are given in ESI, Fig S2). As seen from TEM images (Fig S2), the produced $\mathrm{Ag}$ nanoparticles were almost spherical with a diameter of 20-40 $\mathrm{nm}$. The Au particles obtained have a diameter of $50 \pm 5 \mathrm{~nm}$ with a mix morphology of quasi-hexagon 
and spheres. In the case of platinum, smaller particles of $2.8 \pm$ $0.7 \mathrm{~nm}$ diameter were assembled to give larger spheres with an average diameter of $27.0 \pm 7.9 \mathrm{~nm}$. X-ray diffraction (XRD) and STEM-EDS analysis clearly supports the obtained $\mathbf{P}_{\mathbf{5}} \mathbf{W}_{\mathbf{3 0}} @ \mathbf{M}$ (M $=\mathrm{Au}, \mathrm{Ag}$, and $\mathrm{Pt}$ ) nanoparticles where the cristalline nature of nanoparticles and the presence of the Preyssler POM were confirmed (Fig. S3 and Figs. S25-S27 respectively). In the Raman spectra of POM@MNPs (Figs. S4-S5) no specific interaction could be observed between $\mathrm{P}_{5} \mathrm{~W}_{30}$ and $\mathrm{Au}$ and Pt NPs, while the presence of $\mathrm{Ag}$ induces a $6 \mathrm{~cm}^{-1}$ downshift of the main band, corresponding to $\mathrm{W}=\mathrm{O}$ stretch. The colloids obtained were stable against aggregation for over two months.

In the second part of this work, a bis-porphyrin copolymer with pyridinium spacers was obtained by the electropolymerisation of zinc- $\beta$-octaethylporphyrin (ZnOEP) in the presence of porphyrin functionalized by two pyridyl groups at the meso positions 5 and 10 ( is $-\mathbf{H}_{\mathbf{2}} \mathbf{P h}_{\mathbf{2}} \mathbf{P y}_{\mathbf{2}} \mathbf{P}$ ) (step II in Scheme 1 and Fig. S6). Zinc-based porphyrin and free base porphyrin were chosen in order to form a bis-porphyrin copolymer which absorbs more visible range in order to increase the efficiency of generating a photocurrent. The electropolymerization process is based on a nucleophilic attack of the pyridyl groups onto electrogenerated

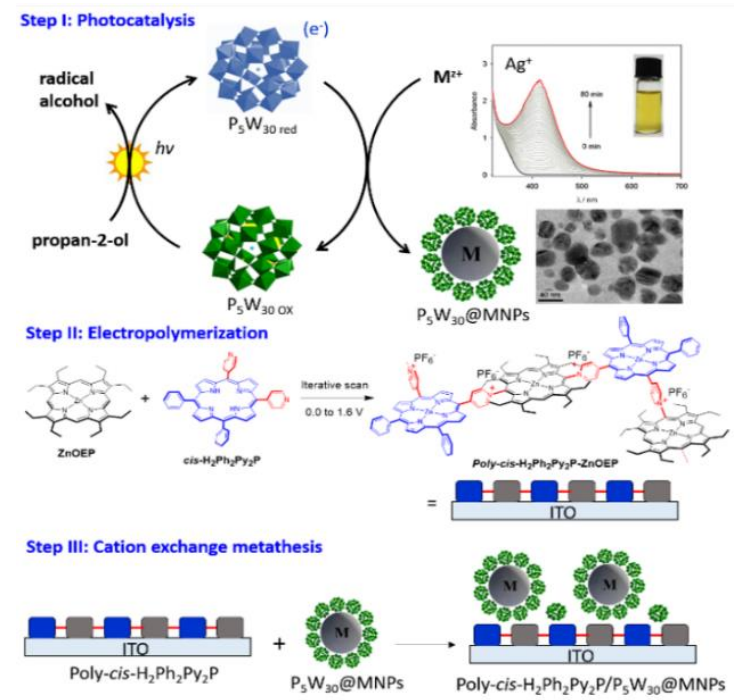

Scheme 1. Procedure for the preparation of Poly-cis- $\mathbf{H}_{2} \mathbf{P h} \mathbf{h}_{2} \mathbf{P y} \mathbf{P}_{2} \mathbf{P} / \mathbf{P}_{5} \mathbf{W}_{\mathbf{3}} \mathbf{N P s}$. Inset of step I: absorption spectra of silver nanoparticles in aqueous solution, obtained under UV-vis irradiation of $\mathrm{Na}_{14}\left[\mathrm{NaP}_{5} \mathrm{~W}_{30} \mathrm{O}_{110}\right]\left(\mathrm{P}_{5} \mathrm{~W}_{30}\right)$ with the corresponding metal ions $\left(2 \mathrm{Ag}^{+} \mathrm{SO}_{4}{ }^{2-}, 0.2 \mathrm{mM}\right)$, in the presence of $0.13 \mathrm{M}$ propan-2-ol and photo of the getting metal nanoparticles in solution. TEM image of $\mathbf{P}_{5} \mathbf{W}_{\mathbf{3 0}} @ \mathrm{Ag}$.

ZnOEP $^{2+}$ dications (Fig. S7) leading to the formation of one copolymer of porphyrins with dipyridinium spacers via a $\mathrm{E}\left(\mathrm{EC}_{\mathrm{N} \text { meso }} \mathrm{EC}_{\mathrm{B}}\right)_{\mathrm{n}} \mathrm{E}$ mechanism. ${ }^{\mathbf{C}} \mathbf{C i s}-\mathrm{H}_{\mathbf{2}} \mathbf{P h}_{\mathbf{2}} \mathbf{P y} \mathbf{2}_{\mathbf{2}} \mathbf{P}$ functionalized by two pyridyl groups was chosen to prepare 1D copolymer.

Electrochemical quartz cristal microbalance (EQCM, Fig. S8) measurements performed during the electropolymerisation allowed to determine that the mass of deposited polymer is equal to $9.4 \mu \mathrm{g} \mathrm{cm}{ }^{-2}$ after $\mathrm{n}=25$ iterative scans. The surface morphology of the film was studied by tapping mode Atomic Force Microscope (AFM). Poly-cis- $\mathbf{H}_{2} \mathbf{P} \mathbf{y}_{2} \mathbf{P h}{ }_{2} \mathbf{P}-\mathbf{Z n O E P}$ appears as tightly packed coils with average diameters of $100 \pm 10 \mathrm{~nm}$ and a height of $13.0 \pm 1.0 \mathrm{~nm}$ (Fig. S9). Note that the coils were not observed in the case of the bare ITO electrode and are thus attributed to the copolymers (Fig. S10). Phase imaging mode show clearly for $n=25$, ITO slide is fulled covered by Poly-cis$\mathbf{H}_{2} \mathbf{P y}_{2} \mathbf{P h}_{2} \mathbf{P}$-ZnOEP (Fig. S11).

In the final step (step III in Scheme 1), the $\mathbf{P}_{\mathbf{5}} \mathbf{W}_{\mathbf{3 0}} @ \mathbf{M N P s}$ were introduced at the surface of the Poly-cis- $\mathbf{H}_{2} \mathbf{P y} \mathbf{P}_{2} \mathbf{P h} \mathbf{P}$-ZnOEP film via the ligand exchange with $\mathrm{POM}^{\mathrm{n}-}$ or $\mathbf{P}_{\mathbf{5}} \mathbf{W}_{\mathbf{3 0}} @ \mathrm{MNPs}$ replacing the $\mathrm{PF}_{6}$ - counterions. Quartz Cristal Microbalance ( $\mathrm{QCM}$ ) was employed to monitor the mass changes during this process (Figs. S12-S14). The immobilization kinetics were quite different for the three metals: the mass of $\mathbf{P}_{\mathbf{5}} \mathbf{W}_{\mathbf{3 0}} @$ AuNPs reached the plateau after 1 hour, the mass of $\mathbf{P}_{5} \mathbf{W}_{\mathbf{3 0}} @ \mathbf{P t N P s}$ increased linearly with time (up to 5 hours), while the incorporation kinetics of $\mathbf{P}_{\mathbf{5}} \mathbf{W}_{\mathbf{3} 0} @$ @gNPs exhibited a fast increase of mass during the first hour followed by a slow increase during the next 4 hours. For instance, after the first 0.5 hour, the immobilized amount of $\mathbf{P}_{5} \mathbf{W}_{\mathbf{3 0}} @$ @gNPs was $2.82 \mu \mathrm{g} . \mathrm{cm}^{-2}$ and reached 5.47 $\mu \mathrm{g} . \mathrm{cm}^{-2}$ after 5 hours (Table S1). These different behaviours could be mainly attributed to the differences in size and morphology of the three metal nanoparticles. UV-Vis spectra showed slight interaction between the $\mathbf{P}_{\mathbf{5}} \mathbf{W}_{\mathbf{3 0}} @ \mathbf{M N P s}$ and the porphyrin (Fig. 1B and Fig. S15). XPS analysis of the obtained films confirms the success of the immobilization of $\mathbf{P}_{5} \mathbf{W}_{30} @ \mathbf{M N P s}$ (or $\mathbf{P}_{5} \mathbf{W}_{\mathbf{3 0}}$ ) even if some $\mathrm{PF}_{6}{ }^{-}$still remained in the film (Figs. S16-S21). Detailed analysis of XPS spectra reveals
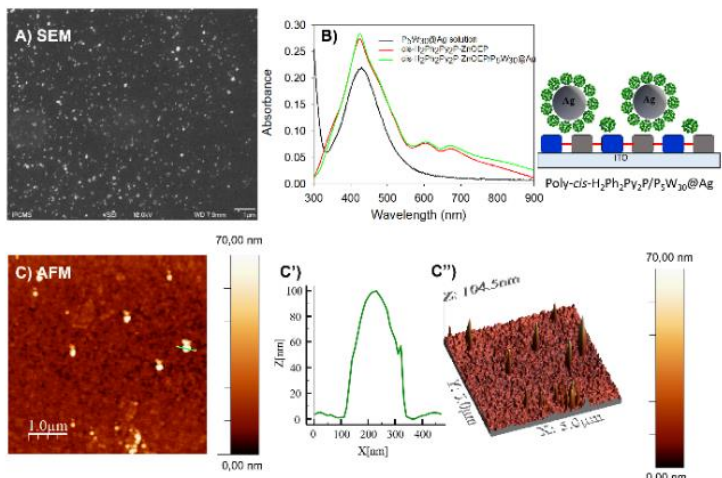

Figure 1. A) SEM of Poly-cis- $\mathrm{H}_{2} \mathrm{Py}_{2} \mathrm{Ph}_{2} \mathrm{P}-\mathrm{ZnOEP} / \mathrm{P}_{5} \mathbf{W}_{30} @ \mathrm{Ag}$ on ITO. B) UV-vis spectra of the modified ITO electrode Poly-cis- $\mathbf{H}_{2} \mathbf{P h}_{2} \mathbf{P y} \mathbf{P}_{2} \mathbf{P}-\mathbf{Z n O E P} / \mathbf{P}_{5} \mathbf{W}_{30} @ A g$ compared with Poly-cis- $\mathbf{H}_{2} \mathbf{P h}_{2} \mathbf{P y}_{2} \mathbf{P}-\mathbf{Z n O E P}$ and $\mathbf{P}_{5} \mathbf{W}_{30} @ A g$. C) Tapping mode AFM topography of Poly-cis- $\mathbf{H}_{2} \mathbf{P h}_{2} \mathbf{P y}_{2} \mathbf{P}-\mathbf{Z n O E P} / \mathbf{P}_{5} \mathbf{W}_{30} @ \mathbf{A g}, \mathrm{C}^{\prime}$ ) section analysis of the aggregate marked by a green line and $C^{\prime \prime}$ ) 3D View

signals characteristics to $\mathrm{Ag}^{18}, \mathrm{Au}$ and $\mathrm{Pt}^{19}$ present at metallic state in the film as well as full oxidation form of tungsten (W(VI)) in $\left[\mathrm{NaP}_{5} \mathrm{~W}_{30} \mathrm{O}_{110}\right]^{14-} .20$ The surface morphology of the final film obtained on ITO electrode was studied using Scanning Electron Microscopy (SEM Figs. S22-S24) and tapping mode AFM (Figs. S28-S30) and. $\mathbf{P}_{\mathbf{5}} \mathbf{W}_{\mathbf{3 0}} @ \mathbf{M N P s}$ are easily detected with homogeneous dispersion. Their sizes are consistent with the morphology observed for the TEM pictures of the $\mathbf{P}_{5} \mathbf{W}_{30} @ M N P s$ (Fig. 1 and Fig. S2). 
The first positive effect obtained by the addition of nanoparticles is on the charge transfer resistance of the Polycis- $\mathbf{H}_{2} \mathbf{P} \mathbf{Y}_{2} \mathbf{P h}_{\mathbf{2}} \mathbf{P}-\mathbf{Z n O E P} / \mathbf{P}_{5} \mathbf{W}_{\mathbf{3 0}} @ M N P s$ films. This was studied using electrochemical impedance spectroscopy (EIS) (Fig. S31). In the absence of $\mathbf{P}_{\mathbf{5}} \mathbf{W}_{\mathbf{3 0}} @ \mathbf{M N P s}$ the EIS data were fitted using an equivalent circuit containing the parallel combination of the charge transfer resistance $\left(R_{c t 1}\right)$ and capacitance $\left(C_{1}\right)$ (Fig. S32). In the presence of $\mathbf{P}_{\mathbf{5}} \mathbf{W}_{\mathbf{3 0}} @ \mathbf{M P N}$ a circuit containing a second parallel $R_{\mathrm{ct} 2}$ and $C_{2}$ combination had to be used in order to fit the data with good accuracy (Fig. S33). It was observed that the films bearing the $\mathbf{P}_{\mathbf{5}} \mathbf{W}_{\mathbf{3 0}} @ \mathbf{M N P s}$ exhibit a lower charge transfer resistance across the film ( $R_{\mathrm{ct} 1}$ decreases by about $200 \Omega$ ) (Table S2). The presence of MNPs in fact catalyze the exchange of electron with the reversible redox mediator couple $\mathrm{I}_{3}{ }^{-} / \mathrm{I}^{-}$which is a slow process with ITO electrode and reduce the charge transfer resistance $\left(R_{c t 1}\right)$. The existence of the second $R_{c t 2} / C_{2}$ parallel combination in the high frequency range could be interpreted as the participation of the $\mathbf{P}_{\mathbf{5}} \mathbf{W}_{\mathbf{3} 0} @ \mathbf{M N P s}$ in the

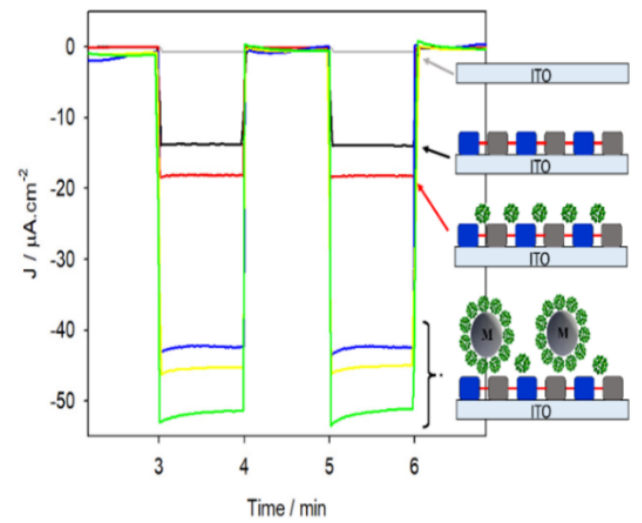

Figure 2. Photoelectrochemical responses of Poly-cis- $\mathrm{H}_{2} \mathbf{P} y_{2} \mathbf{P h} \mathbf{2}_{2} \mathbf{P}-\mathrm{ZnOEP}$, Poly-cis- $\mathrm{H}_{2} \mathrm{Py}_{2} \mathrm{Ph}_{2} \mathrm{P}-\mathrm{ZnOEP} / \mathrm{P}_{5} \mathbf{W}_{30}$, and Poly-cis- $\mathrm{H}_{2} \mathrm{Py}_{2} \mathrm{Ph}_{2} \mathbf{P}-\mathrm{ZnOEP} / \mathrm{P}_{5} \mathbf{W}_{30}$ @MNPs ( $\mathrm{M}=\mathrm{Ag}$ (green curve), Au (yellow curve) or Pt (blue curve)) under on-off light illumination from a $300 \mathrm{~W}$ Xe arc lamp (with $\lambda>385 \mathrm{~nm}$ long pass filter) in $\mathrm{H}_{2} \mathrm{O}$ containing $\mathrm{I}_{3}-5 \mathrm{mmol} \mathrm{L}^{-1}$ and $\mathrm{I}^{-} 0.5 \mathrm{~mol} \mathrm{~L}^{-1}$. BIAS potential: $0.1 \mathrm{~V}$.

charge transfer as a relay between the redox species and the polymer film. Consequently, a first electron transfer could happen at the nanoparticle/electrolyte interface followed by a second electron transfer at the nanoparticle/polymer film interface.

The second positive effect obtained by the addition of the nanoparticles to the Poly-cis- $\mathbf{H}_{2} \mathbf{P y}_{2} \mathbf{P h}{ }_{2} \mathbf{P}$-ZnOEP film is on the photocurrent (Fig. 2 and Table S3). Very close measurements were obtained with $\lambda=400 \mathrm{~nm}$ or $\lambda=385 \mathrm{~nm}$ long pass filters (Fig. S38). It must be noticed here that the presence of the POM alone also promotes the photocurrent and reduces the charge transport $\left(R_{c t 1}\right.$ decreases by about $100 \Omega$ ), but these effects are facilitated even more by the $\mathbf{P}_{5} \mathbf{W}_{30} @ M N P s$. Comparing the three types of $\mathbf{P}_{5} \mathbf{W}_{30} @$ @NPs shows that the three metals have nearly a similar effect on the $R_{\mathrm{ct} 1}$ Thus, the enhancement of the photocurrent is observed with $\mathrm{Ag}, \mathrm{Au}$, and Pt $\mathbf{P}_{5} \mathbf{W}_{30} @$ MNPs in same order of magnitude. While this enhancement of the photcurrent should be regarded with care because the values are quite comparable, the effect of the particles morphology, particles dispersion on the film and the immobilized quantity, etc., specific to each of the three particles (Figs. S22-S27), should not be neglected. In particular, $\mathbf{P}_{5} \mathbf{W}_{\mathbf{3 0}} @ \mathbf{A g}$ is spread more uniformly on the film surface than the other particles.
The contribution of nanoparticles surface plasmon excitation to the enhancement of photocurrent was checked by Raman experiments, obtained with excitations at $457 \mathrm{~nm}$ (i.e. the porphyrin Soret region) (Fig. S34) and at $514 \mathrm{~nm}$ (i.e. the Q-band region) (Fig. S35). Results clearly showed the SERS effect of Ag, as the intensity of the porphyrin bands was enhanced significantly. On the contrary, the Raman spectra of the films containing gold nanoparticles did not show any enhancement of the signal. Although $\mathbf{P}_{\mathbf{5}} \mathbf{W}_{\mathbf{3 0}} @ \mathbf{A u}$ exhibited a surface plasmon band in the visible range (Fig. S2), a SERS effect was not observed even when the soaking time was increased (Fig. S36). Thus, no SERS effect was observed probably because the laser irradiation induces a fast degradation of the film. On the other hand, $\mathbf{P}_{5} \mathbf{W}_{\mathbf{3 0}} @ \mathbf{P t}$ showed no surface plasmon on the UV data but only a SERS effect on the Raman spectra. The SERS effect is believed to arise from an increase in local electric fields (electromagnetic mechanism) and charge transfer effects (chemical mechanism). Whereas the excitation of plasmon resonance and lightning-rod effect on high surface curvature or at sharp edges can both contribute to the increase of electric field for $\mathrm{Ag}$ and $\mathrm{Au}$ nanoparticles, it is suggested that the lightning-rod effect mainly contributes for Pt nanoparticles. Therefore, the participation of nanoparticles surface plasmon to the enhancement of photocurrent is not clearly proven.

Increasing nanoparticles density (via increasing the contact time between the Poly-cis- $\mathbf{H}_{2} \mathbf{P y} \mathbf{P}_{\mathbf{2}} \mathbf{P h} \mathbf{}_{\mathbf{2}} \mathbf{P}-\mathbf{Z n O E P}$ film and the solution of

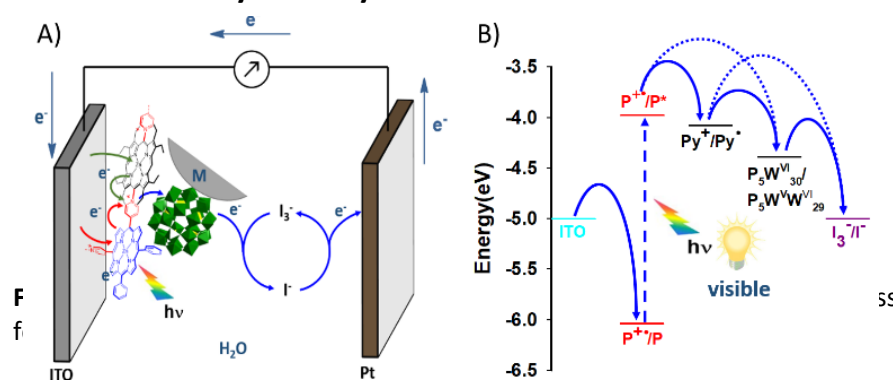

$\mathbf{P}_{5} \mathbf{W}_{30} @ \mathbf{A g}$ ) induces a decrease of the photocurrent. This can be explained by the electrostatic repulsion between the negatively charge of the $\mathbf{P}_{\mathbf{5}} \mathbf{W}_{\mathbf{3 0}} @ \mathbf{A g}$ fixed at the surface which becomes more and more important and the negative charge of the $\mathrm{I}_{3}{ }^{-} / \mathrm{I}^{-}$ ions (Fig. S37).

In the light of these data, the photo-electric conversion mechanism of Poly-cis- $\mathbf{H}_{2} \mathbf{P y}_{2} \mathbf{P h}_{2} \mathbf{P}-\mathbf{Z n O E P} / \mathbf{P}_{5} \mathbf{W}_{30} @ M N P s$ film could be explained by the following processes: (1) the band-gap excitation from HOMO to LUMO of the porphyrin macrocycle under illumination (the ITO conduction band supplement electrons to the HOMO of porphyrin), (2) the electron transfer from the LUMO of porphyrin to the pyridinium spacer, (3) the reduced pyridine radicals relay electrons to WVIPOM (4) the reduced $W^{\vee} P O M$ transmit electrons to the redox mediator $I_{3}{ }^{-}$, (5) the generated $\mathrm{I}^{-}$is reoxidized at the Pt counter electrode which gave electrons to the conduction band of the ITO electrode (Fig. 3). As the metal nanoparticles are surrounded by the POM, they could enhance the electron transfer in step (3) and (4). In order to validate this mechanism, the energy levels were computed as follows. The energy of porphyrin HOMO level $E$ (Porp ${ }^{+\bullet} /$ Porp) is computed from the oxidation potential of the porphyrin (i.e $1.44 \mathrm{~V}$ vs. NHE, Fig. S7). The energy level of LUMO 
level $E$ (Porp ${ }^{+\bullet} /$ Porp $\left.^{*}\right)$ is computed by subtracting the energy of the band gap (estimated from the excitation energy, $E_{\mathrm{SO} \rightarrow \rightarrow \mathrm{s} 1}$ at $\lambda$ $=668 \mathrm{~nm}$, Fig. S15) to the energy of the HOMO level. A value of $-4.08 \mathrm{eV}$ is obtained for the couple Porp ${ }^{+} /$Porp*. The energy level of the couples $\mathrm{Py}^{+} / \mathrm{Py}^{\circ}, \mathrm{P}_{5} \mathrm{WVI}_{30} / \mathrm{P}_{5} \mathrm{~W}^{\mathrm{V}} \mathrm{WVI}_{29}$ and $\mathrm{I}_{3} / \mathrm{I}^{-}$were $4.27 \mathrm{eV}(-0.23 \mathrm{~V}$ vs. NHE, Fig. S7 and Figs. S39-S41), -4.39 eV ($0.11 \mathrm{~V}$ vs. NHE, Fig. S40) and $-5.00 \mathrm{eV}(+0.50 \mathrm{~V}$ vs. NHE, see footnote $¥)$, respectively, on the absolute scale. The energy level of $\mathrm{Py}^{+} / \mathrm{Py}^{\bullet}$ is lower than the LUMO level of porphyrin and higher than $\mathrm{P}_{5} \mathrm{WVI}_{30} / \mathrm{P}_{5} \mathrm{~W}^{\mathrm{V}} \mathrm{WVI}_{29}$, thus suggesting that the excited porphyrin ( $\mathrm{ZnOEP}$ or $\mathrm{H}_{2} \mathrm{Py}_{2} \mathrm{Ph}_{2} \mathrm{P}$ ) is able to reduce $\mathrm{Py}^{+}$to give $\mathrm{Py}^{\bullet}$ under favorable exothermic process. The Preyssler POM $\left[\mathrm{Na}_{14} \mathrm{P}_{5} \mathrm{~W}_{30} \mathrm{O}_{110}\right]^{14-}$, which is a strong electron acceptor, reoxidizes the pyridyl radical ( $\left.\mathrm{Py}^{\circ}\right)$.

In conclusion, a great enhancement of the photocurrent due to the presence of nanoparticles at the surface of an organicinorganic light sensitive film is presented. The film is composed of a copolymer, obtained via the electropolymerization of zincoctaethylporphyrin (ZnOEP) and bis-pyridyl substituted free base porphyrins ( $c$ is $-\mathbf{H}_{2} \mathbf{P y}_{2} \mathbf{P h}_{2} \mathbf{P}$ ), to which metal nanoparticles $(\mathrm{Au}, \mathrm{Ag}, \mathrm{Pt})$, surrounded by Preyssler type polyoxometalate $\mathbf{P}_{\mathbf{5}} \mathbf{W}_{\mathbf{3 0}}$, were attached by electrostatic interactions. The contribution of polyoxometalates to the increase of the photocurrent was proven in our previous papers, where it was shown that the POM is decreasing the back electron-hole recombination while acting as an electron relay between the pyridinium spacers and the reversible redox mediator $\left(\mathrm{I}_{3}^{-} / \mathrm{I}^{-}\right)$. The novelty of this work is to show that metal nanoparticles (POM@MNPs) enhance the photocurrent even more. The nanoparticles are greatly improving the electronic conductivity of the film while acting as a relay of the electron transfer between the film and the redox mediator.

\section{Conflicts of interest}

There are no conflicts to declare.

\section{Notes and references}

$\ddagger$ The energy level of the couple $I_{3}-/ /$ is calculated from the Nernst equation $\mathrm{E}\left(\mathrm{I}_{3}^{-} / \mathrm{I}^{-}\right)=\mathrm{E}^{\mathrm{O}}\left(\mathrm{I}_{3}^{-} / \mathrm{I}^{-}\right)+0,059 / 2 \log \left[\mathrm{I}_{3}^{-}\right] /\left[\mathrm{I}^{-}\right]^{3} \approx 0.50 \mathrm{~V}$.
1 a) D.-L. Long, R. Tsunashima and L. Cronin, Angew. Chem. Int Ed., 2010, 49, 1736-1758. b) H. Lv, Y. V. Geleii, C. Zhao, J. W. Vickers, G. Zhu, Z. Liu, J. Song, T. Lian, D. G. Musaev, and C. L. Hill, Chem. Soc. Rev., 2012, 22, 7572-7589.

2 M. Sadakane, and E. Steckhan, Chem. Rev., 1998, 98, 219-237.

3 D.-L. Long, R. Tsunashima and L. Cronin, Angew. Chem. Int. Ed., 2010, 49, 1736-1758.

4 C. Costa-Coquelard, D. Schaming, I. Lampre and L. Ruhlmann, Appl. Catal. B Environ, 2008, 84, 835-842.

5 a) C. Allain, D. Schaming, N. Karakostas, M. Erard, J.P. Gisselbrecht, S. Sorgues, I. Lampre, L. Ruhlmann, and B Hasenknopf, Dalton Trans., 2013, 42, 2745-2754. b) I. Ahmed, R. Farha, Z. Huo, C. Allain, X. Wang, H. Xu, M. Goldmann, B. Hasenknopf, and L. Ruhlmann, Electrochim. Acta, 2013, 110, 726734. c) H. M. Asif, Y. Zhou, L. Zhang, N. Shaheen, D. Yang, J. Long, Y. Li, A. Iqbal, and Y. Li, Inorg. Chem., 2017, 56, 9436-9447. d) A Iqbal, H. M. Asif, Y. Zhou, L. Zhang, T. Wang, F. K. Shehzad, and X. Ren, Inorg. Chem., 2019, 58, 8763-8774. e) H. Wu, T. Zhang, C. Wu, W. Guan, L. Yan, Z. Su, Dyes Pigments, 2016, 130, 168-175. f) F. Odobel, M. Séverac, Y. Pellegrin, E. Blart, C. Fosse, C. Cannizzo, C.R. Mayer, K.J. Elliott, and A. Harriman, Chem-Eur. J. 2009, 15, 3130-3138. g) S. X. Zhang, L. Liu, F. B. Li, and Z. L. Du, Inorg, Chim. Acta 2016, 453, 179-185. h) Y. Zhu, Y. Huang, Q. Li, D. Zang, J. Gu, Y. Tang, and Y. Wei, Inorg. Chem., 2020, 59, 2575-2583.

6 a) G. Bazzan, W. Smith, L. C. Francesconi, and C. M. Drain Langmuir, 2008, 24, 3244-3249. b) D. Schaming, R. Farha, H. Xu, M. Goldmann, and L. Ruhlmann, Langmuir, 2011, 27, 132-143. c) I. Ahmed, X. Wang, N. Boualili, H. Xu, R. Farha, M. Goldmann, and L. Ruhlmann, Appl. Catal. A-Gen., 2012, 447-448, 89-99. d) I. Ahmed, R. Farha, M. Goldmann, and L. Ruhlmann, Chem. Commun. 2013, 49, 496-498. e) A. Panagiotopoulos, A. M. Douvas, P. Argitis, and A. G. Coutsolelo, ChemSusChem, 2016, 9, 3213-3219.

7 a) C. Allain, S. Favette, L.M. Chamoreau, J. Vaissermann, L. Ruhlmann, and B. Hasenknopf, Eur. J. Inorg. Chem., 2008, 34333441. b) A. Yokoyama, T. Kojima, K. Ohkubo, and S. Fukuzumi, Chem. Commun. 2007, 39, 3997-3999. c) A. Falber, B. P. B. P. I. Radivojevic, L. Todaro, R. Saleh, L. C. Francesconi, and C. M. Drain, Eur. J. Inorg. Chem., 2009, 2459-2466. d) G. Paille, M. GomezMingot, C. Roch-Marchal, B. Lassalle-Kaiser, P. Mialane, M. Fontecave, C. Mellot-Draznieks, and A. Dolbec, J. Am. Chem. Soc., 2018, 140, 3613-3618.
8 a) L. Ruhlmann, A. Schulz, A. Giraudeau, C. Messerschmidt, and J.H. Fuhrhop, J. Am. Chem. Soc. 1999, 121, 6664-6667. b) Y. Xia, D. Schaming, R. Farha, M. Goldmann, and L. Ruhlmann, New J. Chem, 2012, 36, 588-596.

9 a) Z. Huo, D. Zang, S. Yang, R. Farha, M. Goldmann, B. Hasenknopf, H. Xu, and L. Ruhlmann, Electrochim. Acta, 2015, 179, 326-335. b) I. Azcarate, I. Ahmed, R. Farha, M. Goldmann, X. Wang, H. Xu, B. Hasenknopf, E. Lacôte, and L. Ruhlmann, Dalton Trans., 2013, 42, 12688-12698. c) I. Azcarate, Z. Huo, R. Farha, M. Goldmann, H. Xu, B. Hasenknopf, E. Lacôte, and L. Ruhlmann, Chem-Eur. J., 2015, 21, 8271-8280.

10 J. B. Strong, G. P. A. Yap, R. Ostrander, L. M. Liable-Sands, A. L. Rheingold and R. Thouvenot, J. Am. Chem. Soc., 2000, 122, 639649.

11 T. Zhang, W. Guan, S. Z. Wen, T. Y. Ma, L. K. Yan and Z. M. Su, J. Phys. Chem. C, 2014, 118, 29623-29628.

12 J. Hao, A. Giraudeau, Z. Ping, and L. Ruhlmann, Langmuir, 2008, 24, 1600-1603.

13 A. Henglein, Chem. Rev., 1989, 89, 1861-1873

14 a) X. Xin, J.Y. Lang, T. T. Wang, Y. G. Su, Y.X. Zhao, and X. J. Wang, Appl. Catal. B, 2016, 181, 197-209. b) H. Shia, Y. Yua, Y. Zhanga, X. Fenga, X. Zhaoa, H. Tana, S. U. Khana, Y. Lia, and E. Wang, Appl. Catal. B, 2018, 221, 280-289.

15 a) Y. Wang, and I. A. Weinstock, Chem. Soc. Rev., 2012, 22, 74797496. b) Y. Wang, M. Raula, Y. Wang, O. Zeiri, S. Chakraborty, G. Gan-Or, E. Gadot, and I. A. Weinstock. Angew. Chem. Int. Ed., 2017, 56, 7083-7087.

16 a) C. Bao, X. Liu, X. Shao, X. Ren, Y. Zhang, X. Sun, D. Fan, Q. Wei, H. Ju, Biosensors and Bioelectronics, 2020, 157, 112157. b) R. Solarska, K. Bienkowski, S. Zoladek, A. Majcher, T. Stefaniuk, P. J. Kulesza, and J. Augustynski, Angew. Chemie Int. Ed., 2014, 15, 14196-14200. c) P. Chinnappan, P. Alagarsamy, and R. Ramasamy, J. Nanoscience and Nanotechnology, 2015, 15, 6981-6987. d) H. Shi, Y.Yu, Y. Zhang, X. Feng, X. Zhao, H. Tan, S. U. Khan, Y. Li, and E. Wang, Appl. Cat. B: Env. 2018, 221, 280-289.

17 S. Mandal, P. R. Selvakannan, R. Parischa and M. Sastry, J. Am. Chem. Soc., 2003, 125, 8440-8441.

18 B. J. Jiang, C. G. Tian, G. Song, W. Chang, G. F. Wang, Q. Wu, H. and G. Fu, J. Mater. Sci., 2013, 48, 1980-1985.

19 F. Şen, G. Gökağaç, J. Phys. Chem. C 2007, 111 (15), 5715-5720. 
20 C. H. Sui, Z. Y. Wang, C. Wang, G. D. Zhou, and T. X. Cheng,

Chem. Res. Chin. Univ. 2016, 32, 854-861. 